\title{
Aggregated yield and fishing effort in multispecies fisheries: an empirical analysis
}

\author{
Kai Lorenzen, Oriana Almeida, Robert Arthur, Caroline Garaway, and Sophie \\ Nguyen Khoa
}

\begin{abstract}
Many tropical fisheries are inherently of a multispecies nature, with any given type of fishing gear harvesting a wide range of species. Species-aggregated relationships between fishing effort and yield or catch per unit of effort (CPUE) provide important information for the management of such fisheries, as well as insights into ecosystemlevel responses to fisheries exploitation. We used a model selection approach to study species-aggregated, yield-effort relationships in spatially replicated, multispecies inland fisheries. Of three alternative models considered, the data strongly supported a sigmoid functional form (Akaike weight 0.95 ) over the alternative, asymptotic exponential or quadratic (Schaefer) models (Akaike weights 0.03 and 0.02, respectively). The sigmoid form implies the occurrence of an inflexion point in the rising part of the yield-effort curve and no decline in aggregated yield even at the highest effort levels observed. Aggregated CPUE declines steeply near the origin of the effort scale before stabilizing or rising to a local maximum and then declining inversely with further increases in effort. This highly nonlinear response suggests that extreme caution is required when interpreting aggregated CPUE as an indicator of fishing impacts on exploited communities. Further research is required to identify the mechanisms generating the observed relationship.
\end{abstract}

Résumé : Plusieurs pêches tropicales sont multispécifiques de nature et tout type d'engin de pêche y récolte une gamme étendue d'espèces. Les relations pour l'ensemble des espèces entre l'effort de pêche et le rendement ou les captures par unité d'effort (CPUE) fournissent des informations importantes pour la gestion de telles pêches, ainsi que des perspectives sur les réactions écosystémiques à l'exploitation par la pêche. Nous utilisons une méthodologie de sélection de modèles afin d'étudier les relations rendement-effort pour l'ensemble des espèces dans des pêches intérieures multispécifiques qui se répètent à l'échelle spatiale. Des trois modèles considérés, les données appuient fortement le choix d'une forme fonctionnelle sigmoïde (pondération d'Akaike de 0,95) plutôt que des modèles de rechange asymptotique exponentiel ou quadratique de Schaefer (poids respectifs d'Akaike de 0,03 et de 0,02). La forme sigmoïde implique l'existence d'un point d'inflexion dans la partie croissante de la courbe rendement-effort et l'absence de déclin du rendement de l'ensemble des espèces même aux niveaux les plus élevés d'effort observés. La CPUE de l'ensemble des espèces décline abruptement près de l'origine de l'échelle des efforts avant de se stabiliser ou de remonter pour atteindre un maximum local, pour ensuite diminuer en fonction inverse des augmentations subséquentes de l'effort. Cette réaction qui est loin d'être linéaire indique qu'il faut être très prudent lorsqu'on interprète la CPUE de l'ensemble des espèces comme indicateur des impacts de la pêche sur les communautés exploitées. Des recherches supplémentaires pourraient identifier les mécanismes responsables de la relation observée.

[Traduit par la Rédaction]

\section{Introduction}

Many tropical fisheries are inherently of a multispecies nature, with any given gear type exploiting a wide range of species (Pauly 1979; Welcomme 1985). Species-aggregated yield and catch per unit of effort (CPUE) are important indicators of the exploitation status of such fisheries for two reasons. First, aggregated yield and CPUE relate directly to the production and socio-economic benefits derived from the fishery. Second, they reflect, at least in part, communitylevel responses to exploitation. Aggregated yield and CPUE therefore complement indicators of structural impacts of fishing on exploited communities and ecosystems, such as the mean trophic level of landings, mean size of fish in the catch, or the slope of biomass size spectra (Pauly et al. 1998; Welcomme 1999; Rochet and Trenkel 2003). Aggre-

Received 5 June 2005. Accepted 24 January 2006. Published on the NRC Research Press Web site at http://cjfas.nrc.ca on 6 May 2006.

J18727

K. Lorenzen, ${ }^{1}$ O. Almeida, ${ }^{2}$ R. Arthur, ${ }^{3}$ C. Garaway, ${ }^{4}$ and S. Nguyen Khoa. ${ }^{5}$ Division of Biology, Imperial College London, Silwood Park, Ascot SL5 7PY, UK.

${ }^{1}$ Corresponding author (e-mail: k.lorenzen@imperial.ac.uk).

${ }^{2}$ Present address: Instituto de Pesquisa Ambiental da Amazônia (IPAM), Av. Nazare 669, Centro - 66.035-170 Belem, PA, Brasil.

${ }^{3}$ Present address: MRAG Ltd., 18 Queen Street, London W1J 5PN, UK.

${ }^{4}$ Present address: Department of Anthropology, University College, Gower Street, London WC1E 6BT, UK.

${ }^{5}$ Present address: International Water Management Institute (IWMI), P.O. Box 2075, Colombo, Sri Lanka. 
Fig. 1. Overview of the alternative relationships between fishing effort and ( $a$ ) yield and $(b)$ catch per unit of effort (CPUE): sigmoid (heavy solid line), asymptotic (thin solid line), and quadratic (dashed line) functional form. Yield and effort are in arbitrary units.

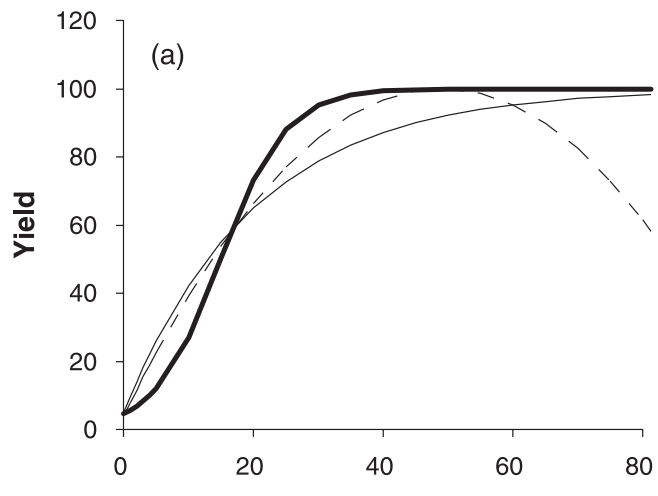

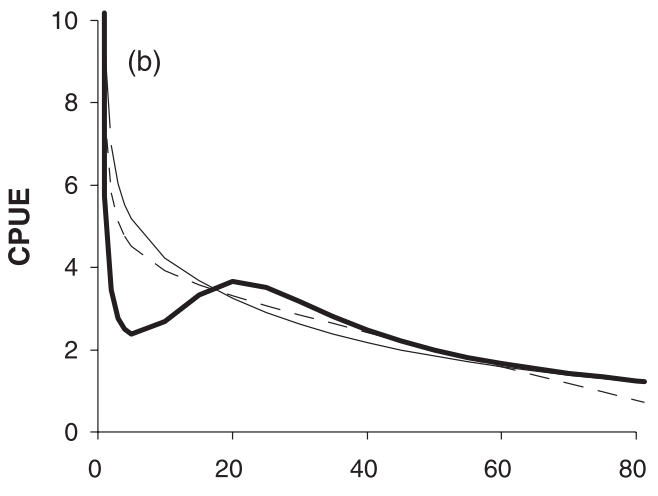

Effort

best fit to the quadratic curve. While this approach has resulted in a good statistical description of the comparative data, it has three shortcomings. First, the a priori assumption of a quadratic functional form imposes a strong, theoretically based constraint and effectively makes the resulting model theoretical rather than empirical (Mangel et al. 2001). Second, the use of transformed variables confounds error structure and functional form and therefore obscures the underlying relationship. Third, fitting of the model to data from ecologically and technologically very heterogeneous systems poses problems in terms of effort standardization and potential confounding factors. For this reason, Bayley (1988) called for systematic comparative studies within more homogeneous systems.

Our study aims to further the empirical analysis of aggregated yield-effort relationships by confronting alternative functional relationships with data collected from ecologically and technologically homogeneous systems. We also reanalyze the data for more heterogeneous systems as used in Bayley (1988). Three candidate models are considered, which represent the major functional forms advanced in previous conceptual or empirical studies (Fig. 1). (i) A sigmoid model as developed conceptually by Welcomme $(1985,1999)$ and supported empirically by Laë (1997) for lagoon fisheries. The model is asymptotic at high effort levels and has an inflexion point in the rising section of the yield curve. Consequently the CPUE curve may show a more or less pronounced local maximum at intermediate effort levels and declines only gradually at higher levels. (ii) An asymptotic exponential model, which shows the same asymptotic behaviour at high effort levels, but does not have an inflexion point in the rising section. It thus implies a monotonous decline in CPUE with increasing effort. This form has been proposed as a conceptual model by Jul-Larsen and van Zwieten (2002). (iii) A quadratic (Schaefer) model, as often assumed for single species stocks and used in multispecies systems by Pauly (1979) and, with transformed variables, Bayley (1988). While our selection of candidate models is inspired by previous empirical and conceptual studies, none of the models have a direct phenomenological basis. The aim of our analysis is the identification of a robust empirical model, rather than the testing of alternative biological hypotheses. Using a model selection approach based on maxi- form a priori, but tests different transformations (none, log, and square-root) of both yield and effort data to obtain the 
mum likelihood estimation (Burnham and Anderson 2002; Johnson and Omland 2004), we account for log-normal error structure without distorting the functional form of the underlying yield-effort relationship.

\section{Materials and methods}

\section{Data}

Primary data were obtained from subsistence-oriented inland fisheries in the Brazilian Amazon and in Laos. In both study areas, the majority of the rural population engages in fishing as part of a diversified semisubsistence livelihood strategy (Garaway 1999; Almeida 2004; Smith et al. 2005). Primary data were collected from four independent study systems: Amazon lakes, Lao nonstocked lakes, Lao stocked lakes, and Lao floodplains (Table 1). Amazon lakes were located in the floodplain of the lower Amazon and ranged in size from 10 to 1200 ha. Their fisheries were exploited by local communities predominantly with gill nets, cast nets, and hook and line. The Lao lakes were much smaller than those studied in the Amazon, covering between 1 and 20 ha in area. Nonstocked lakes contained only native, wild stocks and were exploited by local households on an individual basis, using mostly gill nets and cast nets. Stocked lakes contained populations of exotic species maintained largely by continued stocking, in addition to native wild fish. Exotic species comprised Indian major carp (Labeo rohita, Cirrhinus mrigala) and Chinese carp (Aristichthys nobilis, Hypophthalmichthys molitrix), which do not reproduce naturally in small lakes, and Nile tilapia (Oreochromis niloticus), which established self-reproducing populations in the more eutrophic lakes (Arthur 2004). Only wild fish catches from the stocked lakes were used in the current analysis. Previous studies indicated that stocking of exotic species had no measurable impact on wild fish catches, abundance, or species composition (Lorenzen et al. 1998; Arthur 2004). Catches and abundance of exotic species, on the other hand, were strongly influenced by stocking and cannot therefore be included in the analysis of multispecies yield-effort responses. Stocked lakes were exploited on a communal basis by fishing teams using gill nets and cast nets, and overall effort levels were often low because of either intentional restriction or low incentives to participate in communal harvesting (Garaway 1999). Lao floodplain fisheries are based on a mixture of aquatic habitats that become interconnected during the wet season, including rivers, floodplain lakes, and rice paddies (Nguyen Khoa et al. 2005), and are exploited by a plethora of different gears. For the purpose of this study, wetland areas were delineated on a village basis, and catch and effort were expressed per unit of village wetland area.

Catch and effort data were collected by means of household surveys, with the exception of stocked Lao lakes, where catches were recorded directly by the village administration. Household surveys based on recall of catches by respondents are widely used to quantify catch and effort in subsistenceoriented and recreational fisheries, where diffuse landings make the use of conventional catch assessment surveys all but impossible (Bayley and Petrere 1989; Cahoon et al. 1993; SEAFDEC 2004). Recall of catches by fishers tends to be reasonably accurate as long as recall periods are short (i.e., days up to one week). A comparison of catch weights esti-
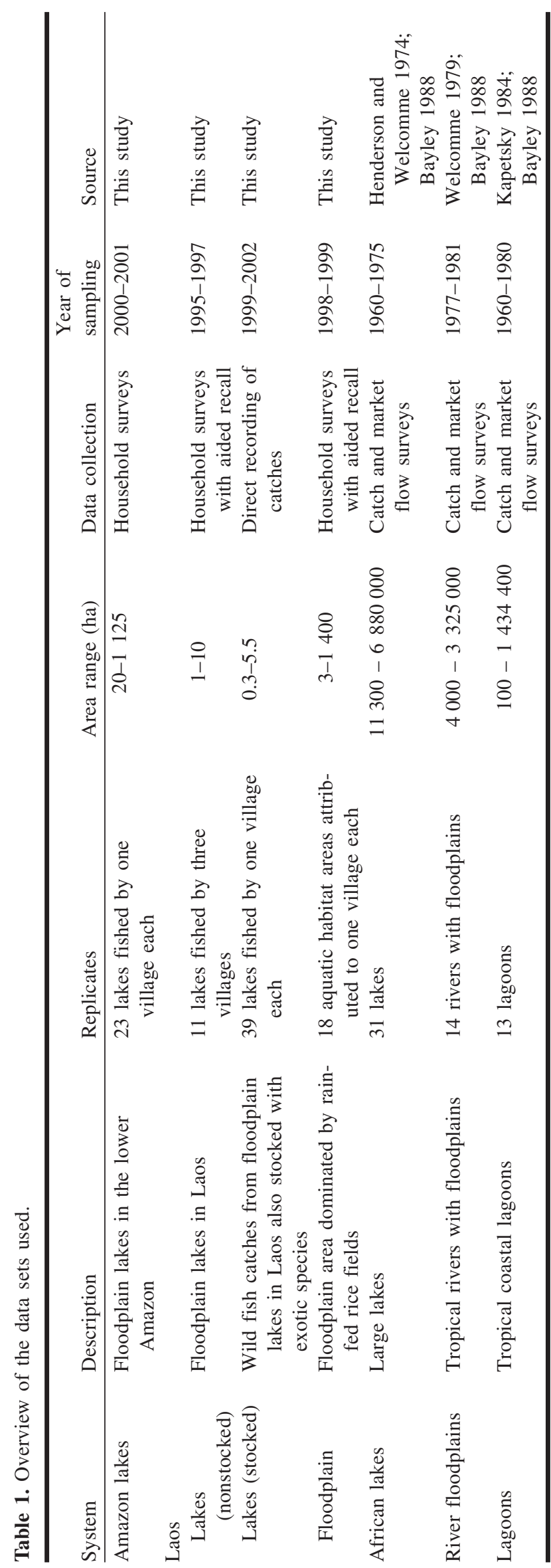

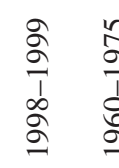

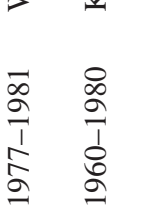

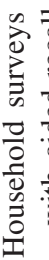
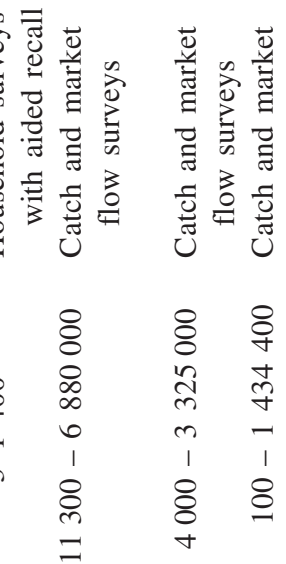

I. ñ

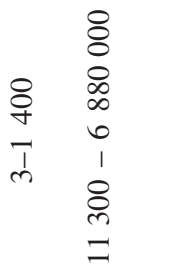

\begin{tabular}{l}
8 \\
8 \\
8 \\
8 \\
8 \\
9 \\
\hline
\end{tabular}

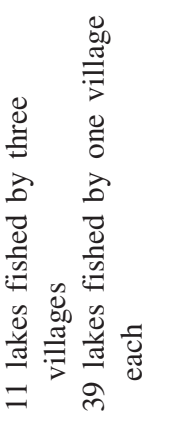

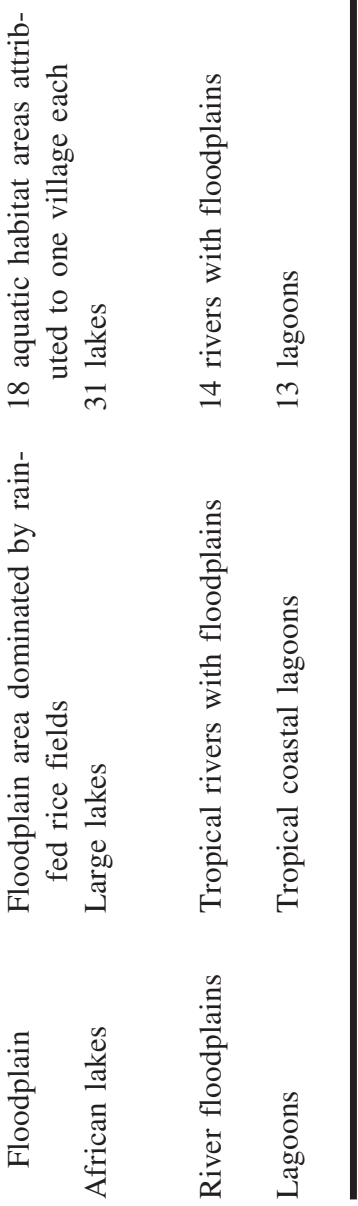

(C) 2006 NRC Canada 
mated by Amazonian fishers with subsequent direct measurement showed that fishers' estimates were within $10 \%$ of the true weight in $70 \%$ of cases and within $20 \%$ in $90 \%$ of cases (G. Moisés, Project Mamiraua, Cx. Postal 38, 69470000 Tefe, AM, Brazil, personal communication). Our surveys were designed with a 1-week recall period, and in Laos visual aids such as sticks and bowls to aid recall were used (Garaway 1999). Surveys covered two 1-week periods in the dry and wet seasons, respectively, in the case of Amazon lake and Lao floodplain fisheries, twelve 1-week periods (one per month) in the case of Lao nonstocked lake fisheries, and continuous village records in Lao stocked lake fisheries. In the Amazon and Lao lake fisheries where fishers often had access to several local lakes, catch and effort data were disaggregated within households and combined by lake.

In the Lao floodplain fisheries, which were exploited by a plethora of gears, effort was measured as hours fished without reference to gear type. In the Amazon and Lao lake fisheries that were exploited by fewer gear types, effort expended by different gear types was standardized as follows (Gulland 1983). The fishing power $P_{g}$ of gear $g$ relative to standard gear $s$ was calculated as the average of the CPUE ratio for the two gear types over all lakes $i$ where both gears were used:

$$
P_{g}=\frac{1}{n} \sum_{i=1}^{n} \frac{\mathrm{CPUE}_{g, i}}{\mathrm{CPUE}_{s, i}}
$$

The combined fishing effort $E_{i}$ of all gears in lake $i$ is then given by

$$
E_{i}=\sum_{g} E_{g, i} P_{g}
$$

Annual yield and fishing effort for each replicate were calculated per unit lake area or per maximum flooded area in the case of the floodplain study. Gear composition was unrelated to total fishing effort per unit area within studies. However, the gears used differed between systems, with the Amazon lake fisheries targeting larger species, while the Lao lake or floodplain fisheries targeted virtually the full size range of fish present. Hence effort measures are comparable within, but not across systems.

We also reanalysed the secondary data used in Bayley's (1988) study. These data were derived predominantly from catch surveys and some market flow studies, mostly conducted as part of United Nations Food and Agricultural Organization (FAO) projects (Henderson and Welcomme 1974; Welcomme 1979; Kapetsky 1984). In all data used in Bayley's (1988) study, effort was expressed in terms of fishers per square kilometre.

\section{Analysis}

Three alternative models, as described above, were fitted to the aggregated yield-effort data. All models had three parameters, did not force the relationship through the origin, and were written with maximum or asymptotic yield $Y_{\max }$ as an explicit parameter. The sigmoid model with an inflexion point in the rising section is of the form

$$
Y(E)=\frac{Y_{\max }}{1+\exp [a(b-E)]}+\varepsilon
$$

where $Y(E)$ is the aggregated yield at aggregated effort level $E$, $Y_{\max }$ is the maximum yield, $a$ determines the steepness of the curve, $b$ is the effort level at which yield equals $50 \%$ of the asymptotic yield, and $\varepsilon$ is a log-normally distributed random error. This model is asymptotic with $Y(E) \rightarrow 0$ for $E \rightarrow-\infty$ and $Y(E) \rightarrow Y_{\max }$ for $E \rightarrow \infty$; hence $Y(0)>0$. The asymptotic exponential model with monotonically declining slope is of the form

$$
Y(E)=Y_{\max }\{1-\exp [-a(E-b)]\}+\varepsilon
$$

where $a$ determines the steepness of the curve, and $b$ is the effort at the origin of the yield curve. The quadratic (Schaefer) model is of the form

$$
Y(E)=Y_{\max }\left(1-\{1-[a(E-b)]\}^{2}\right)+\varepsilon
$$

where $a$ is the inverse of effort at maximum yield, and $b$ is the effort at the origin of the yield curve.

The models were fitted using the method of maximum likelihood. Omitting constant terms, the minimum negative log likelihood $L$ for each of the candidate models $j$ is given by

$$
L_{j}=\frac{n}{2} \ln \left\{\frac{1}{n} \sum_{i=1}^{n} \ln \left(Y_{i}\right)-\ln \left[M_{j}\left(E_{i}, Y_{\max , j}, a_{j}, b_{j}\right)\right]^{2}\right\}
$$

where $n$ is the number of observations, $Y_{i}$ is the observed yield for replicate $i$, and $M_{j}\left(E_{i}, Y_{\max , j}, a_{j}, b_{j}\right)$ is the yield predicted by model $M_{j}$ for effort $E_{i}$ given the maximum likelihood estimate of parameters $Y_{\max , j}, a_{j}, b_{j}$ (Hilborn and Mangel 1997; Burnham and Anderson 2002). Because the same set of models is compared on several independent data sets, the negative $\log$ likelihood $L_{j \text {,combined }}$ of the combined data for each candidate model $j$ may be calculated as the sum of the negative log likelihoods $L_{j, l}$ associated with the same model in the independent systems $l$ (Edwards 1992):

$$
L_{j, \text { combined }}=\sum_{l} L_{j, t}
$$

Note that this is the combined $L$ for model $j$ given separate parameter estimates for each of the independent systems. The combined $L$ thus applies to the common functional form of the model; it does not imply that a joint set of parameters is estimated for all systems.

Because only the differences between $L_{j}$ values of the data given alternative models are of interest, we report likelihoods as

$$
\Delta L_{j}=L_{j}-L_{\min }
$$

where $L_{\min }$ is the minimum $L_{j}$ among the candidate set of models. The relative weight of evidence for each model can be expressed by the normalized likelihood

$$
W_{j}=\frac{\exp \left(-\Delta L_{j}\right)}{\sum_{k=1}^{3} \exp \left(-\Delta L_{k}\right)}
$$

which may be interpreted as the probability that model $j$ is the best model for the given data given the candidate set of models. The expression given here is the Akaike weight $(W)$ 
Table 2. Parameter estimates of the yield-effort models of Amazon lakes and Lao lakes and floodplains.

\begin{tabular}{|c|c|c|c|c|c|c|c|}
\hline System & Model & 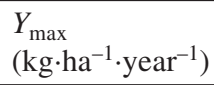 & $\begin{array}{l}a \\
\left(\mathrm{~h}^{-1} \cdot \text { ha } \cdot \text { year }\right)\end{array}$ & $\begin{array}{l}b \\
\left(\mathrm{~h} \cdot \mathrm{ha}^{-1} \cdot \text { year }^{-1}\right)\end{array}$ & $n$ & $\Delta L$ & $W$ \\
\hline \multirow[t]{3}{*}{ Amazon lakes } & Sigmoid & 92 & 0.11 & 30 & 23 & 0.00 & 0.63 \\
\hline & Asymptotic & 2993 & 0.0004 & -1.4 & 23 & 1.25 & 0.18 \\
\hline & Quadratic & 5220 & 0.0001 & -1.6 & 23 & 1.24 & 0.19 \\
\hline \multicolumn{8}{|l|}{ Laos } \\
\hline Lakes (nonstocked) & Sigmoid & 199 & 0.002 & 1967 & 11 & 0.05 & 0.32 \\
\hline \multirow[t]{3}{*}{ Lakes (stocked) } & Sigmoid & 547 & 0.0023 & 1630 & 39 & 0.00 & 0.55 \\
\hline & Asymptotic & 1087 & 0.0001 & -73 & 39 & 0.90 & 0.22 \\
\hline & Quadratic & 1012 & 0.00005 & -74 & 39 & 0.86 & 0.23 \\
\hline \multirow[t]{3}{*}{ Floodplain } & Sigmoid & 129 & 0.018 & 184 & 18 & 0.08 & 0.33 \\
\hline & Asymptotic & 321 & 0.0011 & -8.1 & 18 & 0.16 & 0.31 \\
\hline & Quadratic & 157 & 0.0011 & -7.6 & 18 & 0.00 & 0.36 \\
\hline
\end{tabular}

Note: $Y_{\max }, a$, and $b$ are the model parameters; $n$ is the number of observations; $L$ is the negative log likelihood; and $W$ is the Akaike weight.

Table 3. Parameter estimates of the yield-effort models of African lakes, river floodplains, and lagoons.

\begin{tabular}{|c|c|c|c|c|c|c|c|}
\hline System & Model & $\begin{array}{l}Y_{\max } \\
\left(\mathrm{kg} \cdot \mathrm{ha}^{-1} \cdot \mathrm{year}^{-1}\right)\end{array}$ & $\begin{array}{l}a \\
\left(\text { fishers }^{-1} \cdot \mathrm{km}^{2} \cdot \text { year }\right)\end{array}$ & $\begin{array}{l}b \\
\left(\text { fishers } \cdot \mathrm{km}^{-2} \cdot \text { year }^{-1}\right)\end{array}$ & $n$ & $\Delta L$ & $W$ \\
\hline \multirow[t]{3}{*}{ African lakes } & Sigmoid & 76 & 5.30 & 0.74 & 31 & 0.00 & 0.58 \\
\hline & Asymptotic & 153 & 0.29 & 0.07 & 31 & 0.70 & 0.29 \\
\hline & Quadratic & 155 & 0.11 & 0.07 & 31 & 1.52 & 0.13 \\
\hline \multirow[t]{2}{*}{ River floodplains } & Sigmoid & 99 & 1.04 & 1.97 & 14 & 0.00 & 0.50 \\
\hline & Asymptotic & 97 & 0.32 & -0.22 & 14 & 0.76 & 0.23 \\
\hline \multirow{2}{*}{ Lagoons } & Asymptotic & 120 & 0.18 & -0.52 & 13 & 0.00 & 0.39 \\
\hline & Quadratic & 132 & 0.05 & -1.32 & 13 & 0.19 & 0.32 \\
\hline
\end{tabular}

Note: $Y_{\max }, a$, and $b$ are the model parameters; $n$ is the number of observations; $L$ is the negative log likelihood; and $W$ is the Akaike weight.

(Burnham and Anderson 2002) when all alternative models have the same number of free parameters.

\section{Results}

Akaike weights $(W)$ favour the sigmoid model in our primary data for Amazon lakes and stocked Lao lakes and in the secondary data for African lakes and river floodplains. In the remaining systems, $W$ s are equivocal in their support for the alternative models (Tables 2, 3). When likelihoods are combined among systems (Table 4), Ws strongly favour the sigmoid functional form in our primary data $(W=0.80)$, the secondary data $(W=0.69)$, and overall $(W=0.95)$. Comparison of fitted models with data and examination of standardized residuals for the sigmoid model show that the sigmoid functional form provides a good description of all systems (Figs. 2, 3). Note that because of use of a log-normal error model, deviations of data from the fitted models in the yield and CPUE plots are not the same as the actual residuals.

Empirical support for the sigmoid model points to three regularities in the relationship between effort and aggregated yield or CPUE. These are evident in the data and fitted models for individual systems (Figs. 2, 3), but are best demonstrated when the fitted sigmoid models are normalized and plotted on the same graph (Fig. 4). First, there is no evidence of aggregated yield declining with effort throughout the effort range observed in the systems under study. Second, observed and predicted CPUE are very high near the origin of the effort scale and decline steeply to much lower values at moderate effort levels. This steep decline in CPUE occurs while the overall level of exploitation is very low, with aggregated yield less than $10 \%$ of the system potential. Third, after the initial steep decline, aggregated CPUE tends to rise to a more or less pronounced local maximum before declining very gradually with increasing effort. It is also noticeable that the normalized models for all systems represented in our primary data and to one system (African lakes) represented in the secondary data show a very similar normalized slope (Fig. 4). Only the relationships estimated for the small and comparatively heterogeneous secondary data sets on river floodplains and lagoons show substantially different (lower) normalized slopes. Three distinct regions may be identified in the aggregated relationship with respect to yield and CPUE responses (Fig. 4). In the lightly exploited range (A in Fig. 4), yield is relatively constant, but CPUE declines steeply with increasing effort. This is followed by a moderately exploited range (B), where yield increases almost linearly with effort, while CPUE also increases slightly 
Table 4. Combined likelihood $(L)$ and Akaike weights $(W)$ associated with the alternative models.

\begin{tabular}{|c|c|c|c|c|c|c|}
\hline \multirow[b]{2}{*}{ Model } & \multicolumn{2}{|c|}{ Our studies } & \multicolumn{2}{|c|}{ Bayley (1988) } & \multicolumn{2}{|c|}{ All studies combined } \\
\hline & $\Delta L$ & $W$ & $\Delta L$ & $W$ & $\Delta L$ & $W$ \\
\hline Sigmoid & 0.00 & 0.82 & 0.00 & 0.69 & 0.00 & 0.95 \\
\hline Asymptotic & 2.16 & 0.09 & 1.17 & 0.22 & 3.34 & 0.03 \\
\hline Quadratic & 1.97 & 0.11 & 2.02 & 0.09 & 3.99 & 0.02 \\
\hline
\end{tabular}

Fig. 2. Yield, catch per unit of effort (CPUE), and standardized residuals of yield in relation to fishing effort in the Amazon lake, Lao lake (nonstocked and stocked), and Lao floodplain fisheries. Lines indicate the fitted sigmoid (solid line), asymptotic (long dashed line), and quadratic (short dashed line) models. Standardized residuals are given for the sigmoid model, which shows the best fit overall.

Amazon lakes
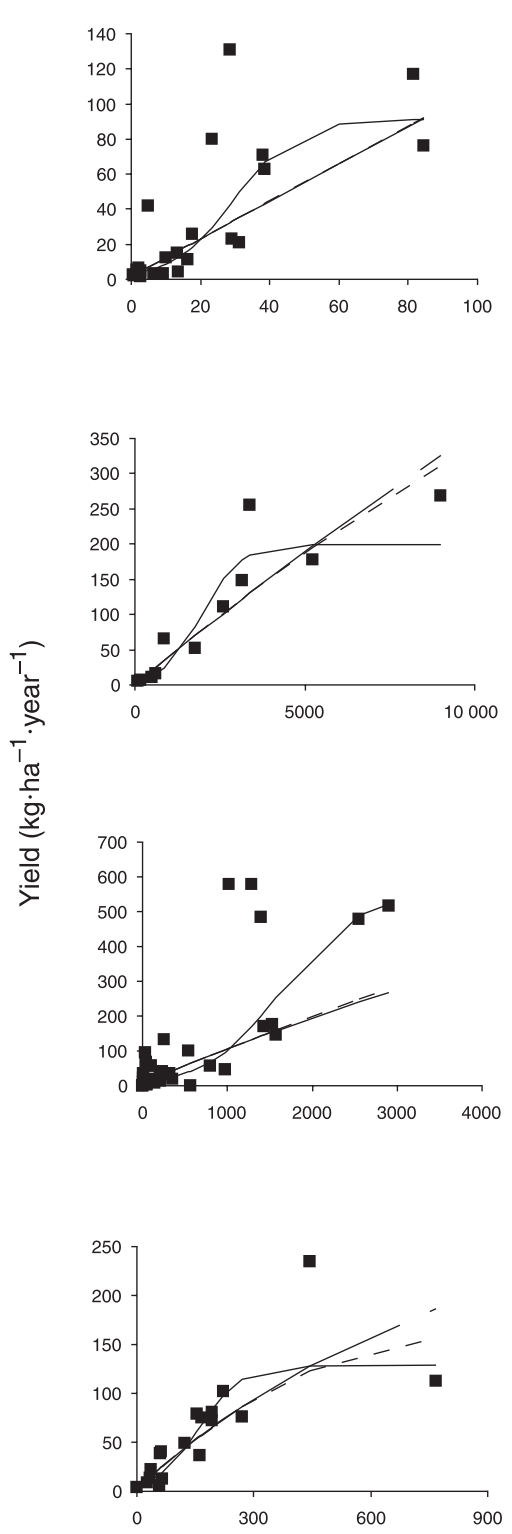

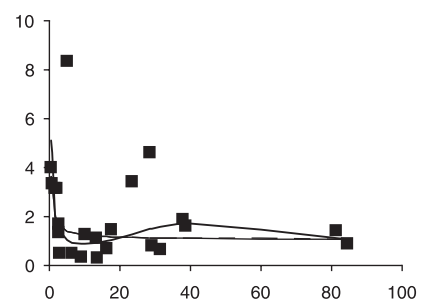

Lao lakes (not stocked)
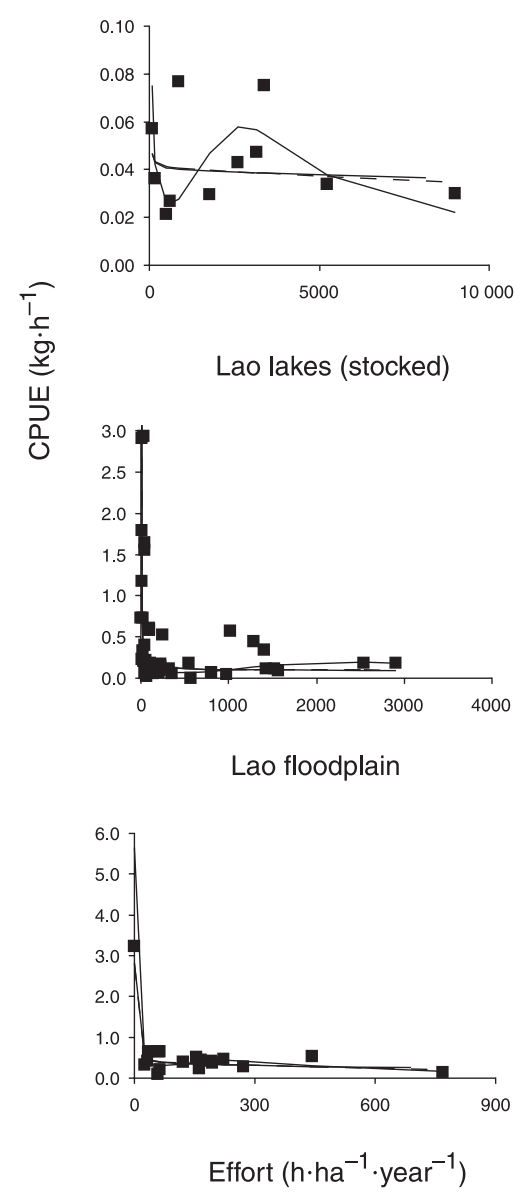
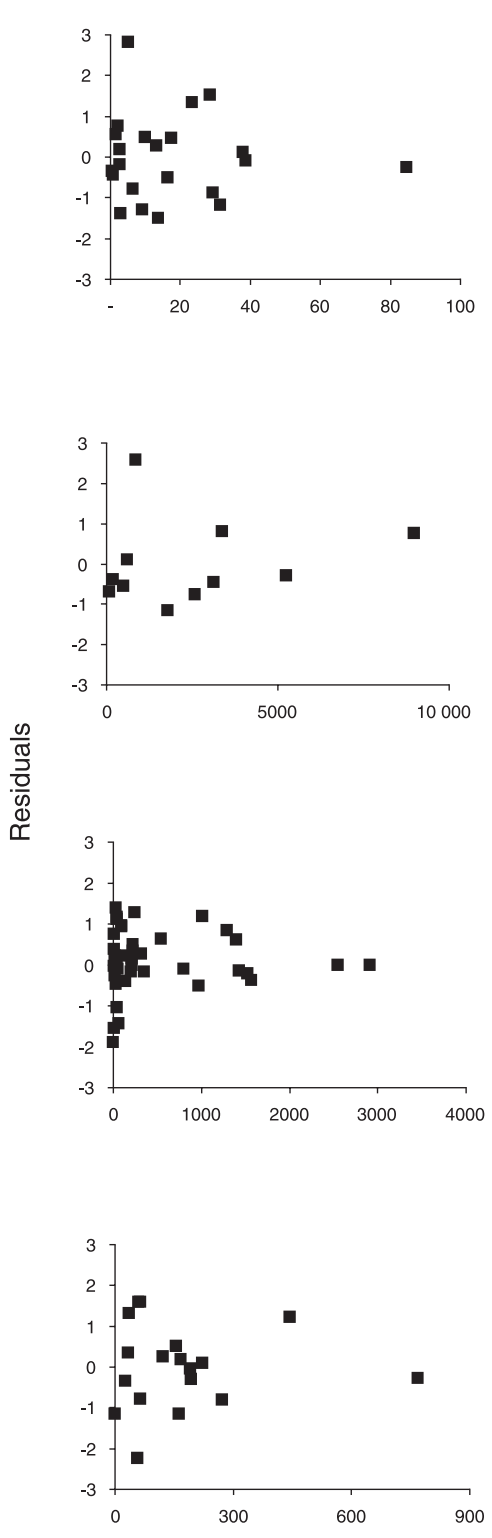
Fig. 3. Yield, catch per unit of effort (CPUE), and standardized residuals of yield in relation to fishing effort in the African lake, river, and lagoon fisheries data compiled by Bayley (1988). Lines indicate the fitted sigmoid (solid line), asymptotic (long dashed line), and quadratic (short dashed line) models. Standardized residuals are given for the sigmoid model, which shows the best fit overall.
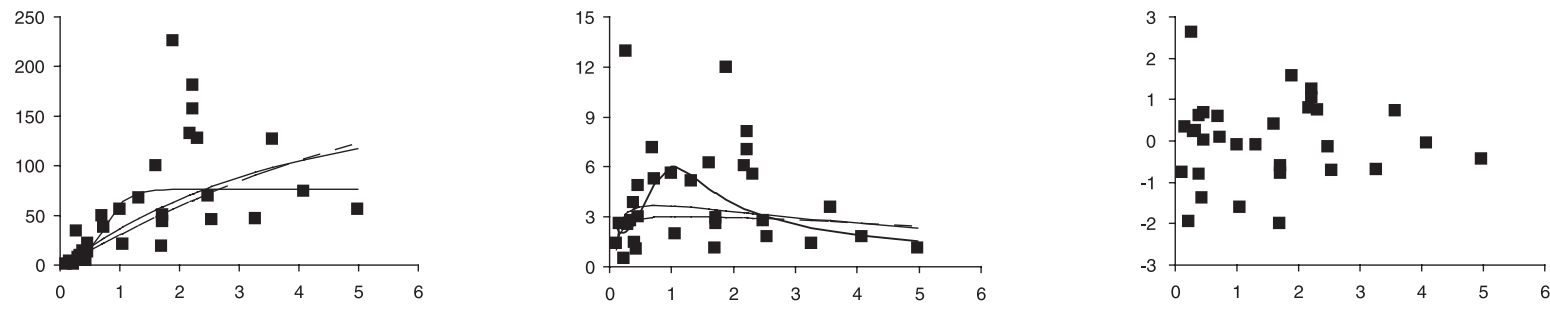

River floodplains
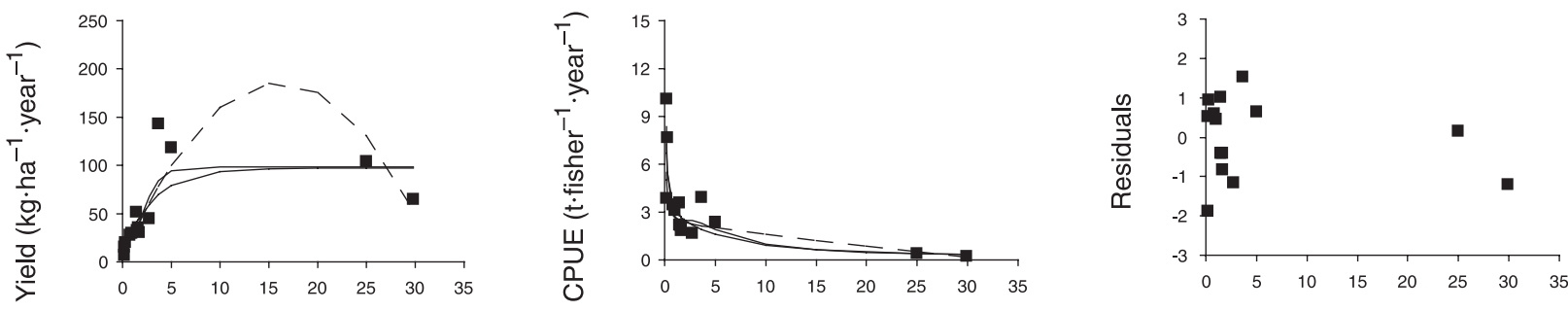

Lagoons
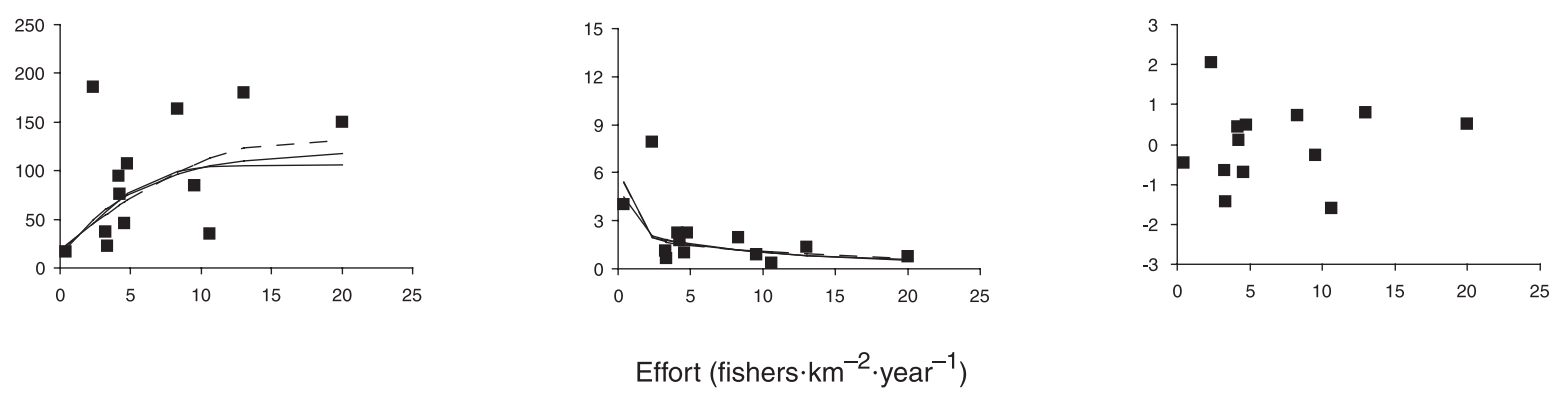

or remains constant. Finally, in the highly exploited range (C), yield is insensitive to effort while CPUE declines inversely.

\section{Discussion}

A sigmoid functional form provides a better empirical model for the multispecies fisheries analysed than either an asymptotic exponential or a quadratic (Schaefer) model. This holds for both our primary studies of relatively homogeneous systems and the data for more heterogeneous systems first analysed by Bayley (1988). The sigmoid model performs best overall, and in no system performs substantially worse than any of the alternative models. We have thus identified a functional form for aggregated yield-effort relationships that appears to hold some generality and is substantially different from the forms assumed or observed in single species fisheries. Key attributes of the relationship within the moderate-to-high effort range have been proposed conceptually or are implicit in earlier studies (Welcomme 1985; Bayley 1988; Laë 1997). Transformation of variables and a priori selection of models, however, may have obscured the true relationships and in particular prevented ap- preciation of its complex behaviour at low effort levels. Our use of a model selection approach, combined with new comparative data from relatively homogeneous systems, has thus allowed us to generalize previously suggested attributes and identify new attributes in aggregated yield-effort relationships.

Our analysis assumes that fishing effort is an independent control affecting the response variables yield and CPUE (i.e., effort is not in turn affected by the response variables). Dynamic effort responses to spatial variation in CPUE would require observations to be treated as joint outcomes of underlying variation in production factors that influence both yield and effort (Walters and Martell 2004). Effort levels are unlikely to be influenced strongly by yield or CPUE in our studies, where fishing involved the majority of the local populations and was carried out in a part-time, subsistenceoriented manner. Effort per unit water area was thus determined by two factors: human population density relative to water area and the level of effort expended by individuals. Population density relative to water area varied widely within study systems, as a result of settlement patterns influenced mainly by agricultural land availability (agriculture being the dominant livelihood activity in the study areas). 
Fig. 4. Normalized (a) yield and $(b)$ catch per unit of effort (CPUE) as a function of normalized effort in the fitted sigmoid models for our primary data (solid lines) and the secondary data (dashed lines). Effort has been normalized relative to the effort at which $50 \%$ of the asymptotic yield is obtained (model parameter $b$ ), while yield has been normalized relative to asymptotic yield. Also shown are the three effort regions: (A) lightly exploited - yield is relatively constant but CPUE declines steeply with increasing effort; (B) moderately exploited - yield increases almost linearly with effort while CPUE remains constant; (C) highly exploited - yield is insensitive to effort while CPUE declines inversely.

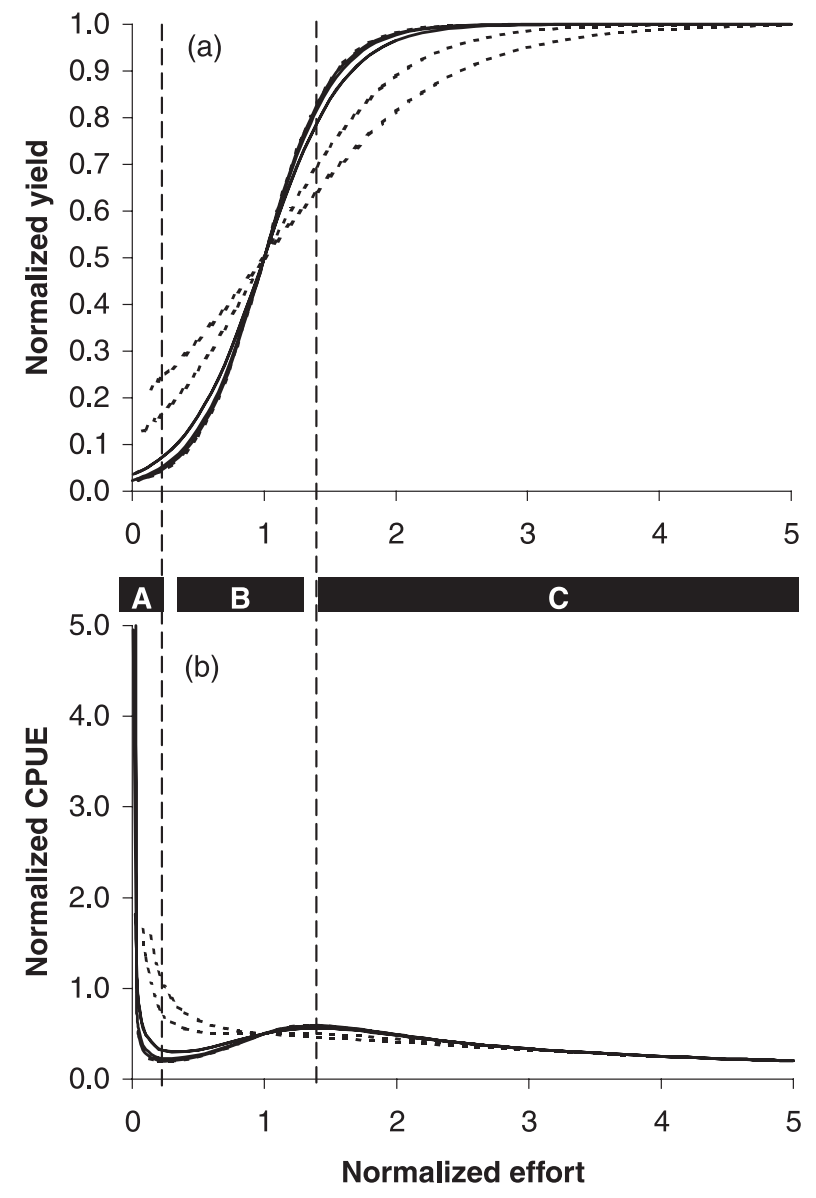

Our household surveys showed that the level of fishing effort expended, and where relevant, its allocation to different water bodies, were influenced primarily by labour availability, convenience of access, and local fishing restrictions rather than CPUE (Garaway 1999; Almeida 2004). No correlations were found between CPUE achieved and average household fishing effort expended in different replicates. While we could not directly examine determinants of effort in the data sets previously analysed by Bayley (1988), it is likely that once again local population density relative to water area is the dominant factor influencing effort variation within the study systems.

The identified relationships have direct implications for the management of multispecies fisheries, in particular those where aggregated yield and CPUE (as opposed to those of only a few species) are important to management stake- holders. This is likely to be the case in tropical inland and coastal fisheries, where high demand exists for a broad range of species. Where such fisheries are highly exploited (range C), aggregated yields will be sustained but CPUE and thus the economic returns to fishers will decline as effort increases. This implies that total yield levels may be maintained even in situations where low opportunity costs for fishers (lack of alternative employment or nutrition) result in very high levels of effort (Allison and Ellis 2001; Jul-Larsen and van Zwieten 2002; Smith et al. 2005). Maintenance of aggregated yield, of course, does not imply absence of changes in ecosystem structure or functioning that may be of conservation concern. Effort reduction within the high-effort range will improve CPUE (i.e., returns to effort), and this can provide incentives for regulation where alternative opportunities exist and institutional arrangements are conducive. In moderately exploited fisheries (range B), effort restriction will reduce aggregated yield proportionally, but not bring increased returns (CPUE) to fishers. Incentives to reduce effort are thus low for all stakeholders. Reducing effort (and yield) to very low levels within range A will always result in a very substantial increase in CPUE, regardless of the initial level of effort. This result is consistent with the observation that drastic fishing restrictions such as no-take reserves tend to increase CPUE or survey abundance substantially by a factor of three on average (Lorenzen et al. 1998; Mosquera et al. 2000). Our analysis also shows, however, that the impact of restrictions is highly nonlinear and that more moderate effort reductions will not bring proportional gains in CPUE. Finally, it is noteworthy that all systems studied included fisheries in all regions of effort $(\mathrm{A}, \mathrm{B}$, C), with about $30 \%$ being lightly, $40 \%$ moderately, and $30 \%$ highly exploited (excluding the stocked Lao lakes, where effort was very restricted and $68 \%$ were lightly exploited). Hence it should not automatically be assumed that tropical inland fisheries are highly exploited, not that effort reduction will necessarily increase yield or CPUE. Whereas aggregated yield and CPUE are unlikely to be the only considerations in the management of multispecies fisheries, both variables are of great interest to key stakeholders. As such, they will be important even where conservation objectives and criteria are the primary focus of management.

The highly nonlinear aggregated CPUE response to effort variation suggests that extreme caution is required when interpreting aggregated CPUE as an indicator of fishing impacts on the exploited community. Unfortunately we do not have sufficient data to provide more than a speculative interpretation of the mechanisms underlying the observed response. Variation in CPUE may arise from variation in stock biomass or in catchability (the effectiveness of fishing), and it is likely that both factors play a part in shaping the aggregated CPUE-effort relationship. While constant catchability and thus proportionality between CPUE and biomass is often assumed in stock assessments, this needs not hold true in all fisheries or over a wide range of effort levels (Hilborn and Walters 1992; Hampton et al. 2005; Polacheck 2006). The steep decline in CPUE at very low fishing effort and biomass removal is very unlikely to reflect a proportional decline in community biomass, particularly given that a further tenfold increase in effort and biomass removal fails to produce any further decline in CPUE. Rather, the initial 
steep decline in CPUE is likely to reflect "hyperdepletion": declining catchability owing to changes in species and size composition of the fish community and the spatial dynamics of fish and fishers (Hilborn and Walters 1992; Walters 2003; Hampton et al. 2005). By contrast, the relative stability of CPUE over a wide range of higher effort levels may result from maintenance of community biomass through successive replacement of large, slow-growing predators by smaller, faster growing forage fish as effort increases (May et al. 1979; Duplisea et al. 1997; Pauly et al. 1998). However, a degree of "hyperstability" (stability of CPUE despite declining biomass) may also be implicated (Hilborn and Walters 1992). The more or less notable increase in CPUE at intermediate effort levels could reflect an increase in community biomass because of release from predation pressure (a trophic cascade), but could also be generated through a transition in the CPUE-biomass relationship from hyperdepletion at low levels to proportionality or hyperstability at higher effort levels. Further research is required to elucidate the mechanisms underlying the identified, apparently general relationship between effort and aggregated yield or CPUE.

Even though our understanding of mechanisms remains limited and speculative, knowledge of the aggregated CPUEeffort relationship aids in the interpretation of observed temporal trends. Rapid declines in aggregated CPUE during the early development of multispecies fisheries, as observed by Myers and Worm (2003), are to be expected and do not imply that the fisheries are highly exploited. Given the overall CPUE-effort relationship, it also seems unlikely that such declines reflect proportional declines in biomass as implied by Myers and Worm (2003), but we cannot conclusively reject this interpretation. It is clear, however, that substantial changes affecting CPUE do occur at very low effort levels and may well be ecologically important (Walters 2003; Hampton et al. 2005). Stabilization of CPUE following initial decline, again observed by Myers and Worm (2003), is also consistent with relationship identified here and may occur despite large increases in effort and possible change in community structure and ecosystem functioning. Overall, this suggests that aggregated CPUE is not a very useful indicator of community or ecosystem impact. Nonetheless, the mechanisms underlying the consistently observed rapid decline in CPUE at low effort levels require further investigation to assess their ecological significance.

\section{Acknowledgements}

This study was supported by the Darwin Initiative, the Department for International Development of the United Kingdom, and the Gordon and Betty Moore Foundation. Guillermo Moisés provided data on the accuracy of Amazon fishers' catch estimates. Comments by Geoff Kirkwood, Carl Walters, Robin Welcomme, Paul van Zwieten, and an anonymous referee improved the manuscript.

\section{References}

Allison, E.H., and Ellis, F. 2001. The livelihoods approach and management of small-scale fisheries. Mar. Policy, 25: 377-388.

Almeida, O.T. 2004. Fisheries management in the Brazilian Amazon. Ph.D. thesis, University of London, UK.
Arthur, R.I. 2004. Adaptive learning and the management of small waterbody fisheries: a case study in Lao PDR. Ph.D. thesis, University of London, UK.

Bayley, P.B. 1988. Accounting for effort when comparing tropical fisheries in lakes, river-floodplains and lagoons. Limnol. Oceanogr. 33: 963-972.

Bayley, P.B., and Petrere, M. 1989. Amazon fisheries: assessment methods, current status and management options. Can. Spec. Publ. Fish. Aquat. Sci. 106: 385-398.

Burnham, K.P., and Anderson, D.R. 2002. Model selection and multi-model inference: a practical information-theoretic approach. Springer, New York.

Cahoon, L.S., Riker, C.A., and Moore, T.F. 1993. Recall bias in the national survey of fishing, hunting, and wildlife associated recreation. In Proceedings of the Survey Research Methods Section, American Statistical Association. Available from http://www. amstat.org/sections/SRMS/Proceedings/papers/1993_083.pdf [accessed 18 May 2005]. pp. 508-513.

Duplisea, D.E., Kerr, S.R., and Dickie, L.M. 1997. Demersal fish biomass size spectra on the Scotian Shelf, Canada: species replacement at the shelfwide scale. Can. J. Fish. Aquat. Sci. 54: 1725-1735.

Edwards, A.W.F. 1992. Likelihood. Johns Hopkins University Press, Baltimore, Md.

Garaway, C.J. 1999. Small waterbody fisheries and the potential for community-led enhancement: case studies in Lao PDR. $\mathrm{Ph} . \mathrm{D}$. thesis, University of London, UK.

Gulland, J.A. 1983. Fish stock assessment: a manual of basic methods. Wiley, Chichester, UK.

Hampton, J., Sibert, J.R., Kleiber, P., Mazunder, M.N., and Harley, S.J. 2005. Decline in Pacific tuna populations exaggerated? Nature (London), 434: 38.

Henderson, H.F., and Welcomme, R.L. 1974. The relationship of yield to morpho-edaphic index and number of fishermen in African inland fisheries. CIFA Occas. Pap. 1.

Hilborn, R., and Mangel, M. 1997. The ecological detective: confronting models with data. Princeton University Press, Princeton, N.J.

Hilborn, R., and Walters, C.J. 1992. Quantitative fisheries stock assessment. Chapman and Hall, London, UK.

Johnson, J.B., and Omland, K.S. 2004. Model selection in ecology and evolution. Trends Ecol. Evol. 19: 101-108.

Jul-Larsen, E., and van Zwieten, P. 2002. African freshwater fisheries: what needs to be managed? NAGA WorldFish Ctr. Quart. 25(3-4): 35-40.

Kapetsky, J.M. 1984. Coastal lagoon fisheries around the world: some perspectives on fishery yields, and other comparative fishery characteristics. Stud. Rev. GFCM 61(1): 97-139. FAO, Rome, Italy.

Kirkwood, G.P. 1982. Simple models for multispecies fisheries. In Theory and management of tropical fisheries. Edited by D. Pauly and G.I. Murphy. International Center for Living Aquatic Resources Management, Manila. pp. 83-97.

Laë, R. 1997. Does overfishing lead to a decrease in catches and yields? An example of two West African coastal lagoons. Fish. Manag. Ecol. 4: 149-164.

Lorenzen, K., Garaway, C.J., Chamsingh, B., and Warren, T.J. 1998. Effects of access restrictions and stocking on small water body fisheries in Laos. J. Fish Biol. 53(S1): 345-357.

Mangel, M., Fiksen, O., and Giske, J. 2001. Theoretical and statistical models in natural resource management and research. In Modeling in natural resource management: development, interpretation and application. Edited by T.M. Schrenk and A.B. Franklin. Island Press, Washington. pp. 57-72. 
Marten, G.G., and Polovina, J.J. 1982. A comparative study of fish yields from various tropical ecosystems. In Theory and management of tropical fisheries. Edited by D. Pauly and G.I. Murphy. International Center for Living Aquatic Resources Management, Manila. pp. 255-283.

May, R.M., Beddington, J.R., Clark, C.W., Holt, S.J., and Laws, R.M. 1979. Management of multispecies fisheries. Science (Washington, D.C.), 205: 267-277.

Myers, R.A., and Worm, B. 2003. Rapid worldwide depletion of predatory fish communities. Nature (London), 423: 280-283.

Mosquera, I., Cote, I.M., Jennings, S., and Reynolds, J.D. 2000. Conservation benefits of marine reserves for fish populations. Anim. Conserv. 4: 321-332.

Nguyen Khoa, S., Lorenzen, K., Garaway, C., Chamsinhg, B., Siebert, D.J., and Randone, M. 2005. Impacts of irrigation on fisheries in rain-fed rice-farming landscapes. J. Appl. Ecol. 42: 892-900.

Pauly, D. 1979. Theory and management of tropical multispecies stocks: a review, with emphasis on the Southeast Asian demersal fisheries. ICLARM Stud. Rev. 1.

Pauly, D., Christensen, V., Dalsgaard, J., Froese, R., and Torres, F. 1998. Fishing down marine food webs. Science (Washington, D.C.), 279: 860-863.

Polacheck, T. 2006. Tuna longline catch rates and in the Indian Ocean: Did industrial fishing result in a $90 \%$ rapid decline in the abundance of large predatory species? Mar. Pol. doi:10.1016/ j.marpol.2005.06.016.
Pope, J.G. 1979. Stock assessment in multi-species fisheries. South China Seas Fisheries Development Coordination Programme. SCS/DEV/79/19. FAO, Rome, Italy.

Ralston, S., and Polovina, J.J. 1982. A multispecies analysis of the commercial deep-sea handline fishery of Hawaii. Fish. Bull. 80: 435-448.

Rochet, M.J., and Trenkel, V.M. 2003. Which community indicators can measure the impact of fishing? A review and proposals. Can. J. Fish. Aquat. Sci. 60: 86-99.

SEAFDEC. 2004. Handbook on collecting fishery statistics for inland and coastal fisheries. Southeast Asian Fisheries Development Center, Bangkok, Thailand.

Smith, L.E.D., Nguyen Khoa, S., and Lorenzen, K. 2005. Livelihood functions of inland fisheries: policy implications in developing countries. Water Policy, 7: 359-383.

Walters, C. 2003. Folly and fantasy in the analysis of spatial catch rate data. Can. J. Fish. Aquat. Sci. 60: 1433-1436.

Walters, C.J., and Martell, S.J.D. 2004. Fisheries ecology and management. Princeton University Press, Princeton, N.J.

Welcomme, R.L. 1979. Fisheries ecology of floodplain rivers. Longman, London, UK.

Welcomme, R.L. 1985. River fisheries. FAO Fish. Tech. Pap. 262. FAO, Rome, Italy.

Welcomme, R.L. 1999. Review of a model for qualitative evaluation of exploitation levels in multi-species fisheries. Fish. Manag. Ecol. 6: 1-20. 